\title{
The effect of resuspension on the fate of total mercury and methyl mercury in a shallow estuarine ecosystem: a mesocosm study
}

\author{
Eun-Hee Kim, Robert P. Mason*, Elka T. Porter, Heather L. Soulen \\ Chesapeake Biological Laboratory, University of Maryland Center for Environmental Science (UMCES), P.O. Box 38, Solomons, \\ MD 20688-0038, USA
}

Received 7 May 2003; received in revised form 2 December 2003; accepted 2 December 2003

\begin{abstract}
Sediments are the major repository of mercury in estuaries and could be a significant source of $\mathrm{Hg}$ to the overlying water column via release from the solid phase during resuspension. There is, however, little information on the effect of resuspension on Hg partitioning and release to the water column. The objective of this study was to determine the effect of resuspension on the cycling of THg and $\mathrm{MeHg}$ between the water column and the sediment. Tidal resuspension was simulated using the MEERC STORM facility. The facility can mimic both realistic bottom shear stress and water column turbulence simultaneously. There were three replicates of each resuspension (R) and no resuspension (NR) mesocosms. Two 4-week experiments were conducted in July and October of 2001: experiment 1 without clams and experiment 2 with clams. Both experiments showed that resuspension of muddy sediment introduced significantly higher particulate $\mathrm{THg}$ to the water column as TSS increased. The results suggest that THg was mostly bound to sediment particles with very little release during the resuspension events. In contrast, particulate $\mathrm{MeHg}$ was significantly lower in the $\mathrm{R}$ tanks where sediment particles with poor $\mathrm{MeHg}$ were dominant in the water column during the resuspension events. Dissolved THg and $\mathrm{MeHg}$ did not change in concert with changes in particulate load, suggesting that the dynamics between dissolved and particulate phases for both THg and $\mathrm{MeHg}$ cannot be explained by an equilibrium partitioning.
\end{abstract}

(C) 2004 Elsevier B.V. All rights reserved.

Keywords: Mercury; Methyl mercury; Resuspension; Distribution coefficient

\section{Introduction}

Estuaries provide an essential link in the global biogeochemical cycling of mercury between the terrestrial and the marine environment. Similar to other metals, only a small fraction of the mercury trans-

\footnotetext{
* Corresponding author. Tel.: +1-410-326-7387; fax: +1-410326-7341.

E-mail address: mason@cbl.umces.edu (R.P. Mason).
}

ported in rivers is exported to the ocean due to the high retention of mercury in estuarine environments (Cossa et al., 1996; Benoit et al., 1998; Mason et al., 1999), mainly as a result of sediment burial. Sediment resuspension is an important process for re-introducing metals into the water column and in the cycling of particles and associated nutrients and contaminants at the sediment-water interface (Bloesch, 1995). In estuarine and coastal environments, bottom-sediment resuspension can be caused by natural events (e.g. tidal currents, wind waves, storm events, and wave- 
current interaction) (Sanford et al., 1991; Arfi et al., 1993) and anthropogenic activities (e.g. dredging and trawling) (Schoellhamer, 1996; Lewis et al., 2001). Sediment resuspension takes place when the bottom shear stress is sufficient to disrupt the cohesion of the bottom materials (Evans, 1994). Resuspension is a function of the properties of bottom sediments such as grain size, type of sediments, organic content, and water content. Once particles are resuspended, they tend to resettle by gravity when the shear stress diminishes and this process of resuspension may occur repeatedly (Bloesch, 1995).

Since resuspension of sediments in shallow aquatic ecosystems controls the movement and redistribution of particles, it can play a major role in the mobility and bioavailability of trace metals in these systems. For example, Simpson et al. (1998) observed in a laboratory experiment that during an 8-h resuspension, acid volatile sulfide (AVS) decreased to values lower than the concentrations of simultaneously extracted metals (SEM), suggesting that a significant fraction of metal sulfide phases were oxidized. As trace metals are likely associated with $\mathrm{FeS}$ phases either through coprecipitation or adsorption, these metals may be released as the FeS phases are oxidized and released, in concert with the oxidized sulfur species, to the overlying water. Thus, resuspension can act as a potential source of toxic metals to the water column, increasing the potential metal bioavailability. The released metal may, however, be quickly scavenged by or coprecipitated with iron and manganese oxides or complexed to organic matter. While studies have focused on other metals, to date there is a paucity of information available on the fate of mercury and methyl mercury during resuspension, or on their potential release from reduced sulfide phases upon resuspension.

A number of laboratory studies have demonstrated that resuspension of sediments results in the release of organic contaminants, such as PAHs and PCBs (Latimer et al., 1999), as well as trace metals, such as $\mathrm{Mn}, \mathrm{Fe}, \mathrm{Zn}, \mathrm{Cu}$, and $\mathrm{Cd}$, into overlying water (Calvo et al., 1991; Petersen et al., 1997; Laima et al., 1998). In contrast, Brassard et al. (1997) concluded from their small reactor experiment that surficial sediments were not significant sources of trace metals into the water column when resuspended. They postulated, however, that this might not be applicable to anoxic sediments from deeper layers because of the potential for oxidative release of metals. However, the degree to which this may occur in the environment is limited.

Overall, the previous laboratory experiments have been limited as they failed to mimic nature (i.e. both realistic bottom shear stress and water turbulence) (Porter et al., in press), have been of short duration, and have used high suspended sediment: water ratios greater than found in nature. Thus, it is not possible to extrapolate from the small scale of these laboratory studies to natural conditions. The objective of this study was, therefore, to investigate the effect of sediment resuspension on the fate and bioavailability of total mercury ( $\mathrm{THg}$ ) and methyl mercury $(\mathrm{MeHg})$ using the new STORM (high bottom Shear realistic water column Turbulence Resuspension Mesocosm) facility designed and developed by Elka Porter (Porter et al., in press). The experimental system can mimic both realistic bottom shear stress and water column turbulence. We conducted two experiments, one in July (experiment 1) and the other in October of 2001 (experiment 2). In experiment 1, no benthic macrofauna was introduced to the mesocosms while in experiment 2, hard clams, Mercenaria mercenaria, were added to the sediment in the mesocosms. Experiment 2 was aimed at investigating the effect of resuspension on the bioavailability of $\mathrm{Hg}$ and its bioaccumulation into clams, as well as the methylation and demethylation of $\mathrm{Hg}$ in the sediment. In this paper, however, the fate of $\mathrm{Hg}$ in the water column will be specifically discussed. A companion paper will discuss the sedimentary dynamics of $\mathrm{THg}$ and $\mathrm{MeMg}$ and their bioaccumulation in zooplankton and clams (Kim et al., 2004).

\section{Material and methods}

\subsection{Mesocosm setup}

Muddy surface sediment was collected from Baltimore Harbor in the spring of 2001 and transferred to a fiberglass holding tank and prepared for each experiment following techniques developed in Porter (1999). The sediment was covered with a black plastic sheet for defaunation (4 days) and it was kept in the holding tank until the experiment. After the top $10 \mathrm{~cm}$ 
layer of sediment was scooped off to remove any remaining live macrofauna, the sediment was transferred to six STORM tanks $\left(1 \mathrm{~m}^{2}\right.$ sediment surface area). The sediment was mixed thoroughly and flattened. Ambient water from the mouth of the Patuxent River, a subestuary of the Chesapeake Bay, MD, USA, was filtered through filtration units (pore size $0.5 \mu \mathrm{m}$ absolute) and carefully added into the tanks without any disturbance of the sediment layer to a depth of $20 \mathrm{~cm}$ above the sediment surface. The mesocosms then underwent an equilibration period (about 2 weeks) with the water column oxygenated by bubbling. During this period, $50 \%$ of water was exchanged daily with filtered ambient water. The final sediment depth was about $10 \mathrm{~cm}$ after the equilibration period. After this period, unfiltered ambient water from the Patuxent River was added to the tanks (total volume of 1000 1) without any sediment disturbance. There were three replicates of resuspension (R) and no resuspension (NR) mesocosms set up for the experiments. Tidal resuspension ( $4 \mathrm{~h}$ on- and $2 \mathrm{~h}$ off-cycles) was simulated using the STORM tank mixing design. In both $\mathrm{R}$ and NR tanks, water turbulence intensity was similar and water mixing was set to have $4 \mathrm{~h}$ onand $2 \mathrm{~h}$ off-cycles in both tanks. Thus, there were both sediment resuspension and water turbulence in the $\mathrm{R}$ tanks while there was water turbulence only in the NR tanks. Water was exchanged daily at a rate of $10 \%$ of the total volume with filtered Patuxent River water to mimic the flushing time scale of the Chesapeake Bay. In addition, water exchange was always performed near the end of the off-phase in order to minimize particle loss in the $\mathrm{R}$ tanks.

The sediment in the mesocosms was transferred to the holding tank after experiment 1 and stored until the next experiment. Experiment 2 was basically set up in a similar manner as experiment 1 . However, a scaled population of about $50 \mathrm{ca}$. $40-\mathrm{mm}$-long clams, M. mercenaria, was placed into the sediment individually by hand after the sediment equilibration period. Hard clams were allowed to bury themselves into the sediments overnight. Those clams that had not buried themselves by the next morning were collected and discarded and replaced with new clams. New clams that again had not buried themselves by the next morning were removed and not replaced. Since negative effects (e.g. inhibition of feeding rate, burrowing, growth, and survival of juveniles and adults) on clams result from salinities below 15 ppt (Grizzle et al., 2001 and references therein), salinity was maintained approximately 19 ppt throughout experiment 2, compared to a salinity of around $14 \mathrm{ppt}$ for experiment 1 .

\subsection{Sample collection}

Water samples were collected every 2-3 days during the on-cycle (sediment resuspension in the $\mathrm{R}$ tanks) by siphoning water from $50 \mathrm{~cm}$ below the surface by gravity flow into a sample bottle. Additionally, on three occasions samples were collected after the cessation of resuspension in all tanks. Water samples were taken separately for $\mathrm{Hg}$ and other variables such as TSS, dissolved organic carbon (DOC), and chlorophyll $a(\mathrm{Chl} a$ ). All sample bottles for $\mathrm{Hg}$ were Teflon and were acid-cleaned according to our established protocols before use (e.g. Mason et al., 1999). Water samples were filtered onto $0.4 \mu \mathrm{m}$ polycarbonate filters for particulate $\mathrm{THg}$ and $\mathrm{MeHg}$. The filters were then stored double-bagged and frozen until subsequent digestion and analysis. The filtrate was collected for dissolved $\mathrm{THg}$ and $\mathrm{MeHg}$ in acidcleaned Teflon bottles and kept frozen. For TSS and particulate organic matter (POM), samples were filtered through pre-weighed $0.7 \mu \mathrm{m}$ Whatman $\mathrm{GF} / \mathrm{F}$ glass fiber filters. POM was calculated from loss on ignition at $450{ }^{\circ} \mathrm{C}$ for $4 \mathrm{~h}$ after the samples had been dried. The samples for Chl $a$ and DOC were filtered in the same way as mentioned above and were sent to the Analytical Service at CBL for analyses.

\subsection{Sample analyses}

\subsubsection{Total mercury}

The filtrates were thawed and oxidized with bromine monochloride $(\mathrm{BrCl})$ for $0.5-1 \mathrm{~h}$ while the particulate filter samples were digested in a solution of 7:3 sulfuric acid/nitric acid in Teflon vials in an oven at $60{ }^{\circ} \mathrm{C}$ overnight prior to $\mathrm{BrCl}$ oxidation. For all samples, excess oxidant was neutralized with $10 \%$ hydroxylamine hydrochloride prior to analysis (Bloom and Crecelius, 1983). The samples were then reduced by tin chloride, sparged, and the elemental Hg trapped on gold traps. Quantification was done by dual-stage gold amalgamation/Cold Vapor Atomic Florescence detection (CVAFS) (Bloom and Fitzgerald, 1988) in 
accordance with protocols outlined in EPA method 1631 (EPA, 1995). A calibration curve with an $r^{2}$ of at least 0.99 was achieved daily. Detection limits for $\mathrm{THg}$ were based on three standard deviations of blank measurements (digestion blanks for filters and $\mathrm{SnCl}_{2}$ bubbler blanks for filtered water). The detection limits for THg were $0.2 \mathrm{pmol} \mathrm{g}^{-1}$ for filters and $0.4 \mathrm{pmol} \mathrm{l}^{-1}$ for filtered water. Analysis of duplicate samples yielded an average RSD of less than $20 \%$. A recovery of estuarine sediment standard reference material (IAEA-405) was greater than $85 \%$.

\subsubsection{Methyl mercury}

Details of the analytical protocols are given elsewhere (Mason et al., 1999; Mason and Lawrence, 1999). Briefly, samples were distilled with a $50 \%$ sulfuric acid $/ 20 \%$ potassium chloride solution (Horvat et al., 1993). A sodium tetraethylborate solution was added to the distillate to convert the nonvolatile $\mathrm{MeHg}$ to gaseous methylethylmercury (Bloom, 1989). The volatile adduct was then purged from solution and recollected on a graphitic carbon column at room temperature. The methylethylmercury was thermally desorbed from the column, and analyzed by isothermal gas chromatography with CVAFS. This method was used for the analysis of $\mathrm{MeHg}$ in both filters and water. A calibration curve with an $\mathrm{r}^{2}$ of at least 0.99 was achieved daily. Detection limits for $\mathrm{MeHg}$ were based on three standard deviations of distillation blanks. The detections for $\mathrm{MeHg}$ were $0.005 \mathrm{pmol}$ $\mathrm{g}^{-1}$ for filters and $0.09 \mathrm{pmol}^{-1}$ for filtered water. Spike recoveries for MeHg were $92 \pm 18 \%$ for filters and $86 \pm 18 \%$ for filtered water.

\subsection{Statistics}

The data of all the sampling days in each system were averaged for statistical analysis. The data analysis was performed using ANOVA to test if there was a significant difference between two treatments (R vs. NR). Data were checked for normality and equal variances and log-transformed if necessary. A nonparametric test (Wilcoxon test) was performed when the assumption of equal variances was not met. Correlation coefficient $(r)$ was obtained using Pearson product-moment correlation to see if there was a linear relation between variables. All the statistical results were reported as significant at a level of $p<0.05$. We used JMP, version 4 by SAS institute, Cary, NC, USA for all the statistical analyses.

\section{Results and discussion}

\subsection{Experiment 1 (without clams)}

\subsubsection{Water column characteristics}

As seen in Fig. 1a, TSS in the R tanks was significantly higher during resuspension, averaging $148 \pm 27 \mathrm{mg}^{-1}$ than that in the NR tanks $\left(10 \pm 0.2 \mathrm{mg}^{-1}\right)$ throughout the experiment period (28 days). Over time, TSS in the R tanks showed a slight decrease for the initial 2 weeks but tended to increase toward the end of the experiment. It should be noted, however, that the R system was accidentally shut off on the 20th day and all the R tanks were not disturbed overnight. The arrow in Fig. 1a shows when the system was down. As mentioned above, there were three additional samplings during the off-cycle in accordance with the on-cycle samplings to assess changes in parameter during the non-resuspension phase (days 12, 18, and 25). Average TSS and other variables during the non-resuspension phase were only compared to the resuspension phase on those corresponding days. Although these data are not shown in the figures, average values $(n=3)$ are presented only when there is a significant difference between the two cycles for all the variables. In that case, average values only for the off-cycle (nonresuspension) were given, as those for the on-cycle $(n=3)$ were similar to average values for the entire sampling period $(n=11)$. Average concentration of TSS in the R tanks decreased significantly during the off-cycle $\left(20 \pm 1 \mathrm{mg} \mathrm{l}^{-1}, n=3\right)$, compared to the on-cycle.

Similarly, POM was significantly higher in the R tanks than the NR tanks, averaging $22 \pm 3$ and $5.4 \pm 0.1 \mathrm{mg}^{-1}$, respectively (Fig. 1b). Average POM decreased significantly in the $\mathrm{R}$ tanks during the off-cycle $\left(5.2 \pm 0.2 \mathrm{mg} \mathrm{l}^{-1}, n=3\right)$, compared to the on-cycle. The result confirms that POM was introduced to the water column as TSS increased during resuspension events. There was a significant positive correlation between TSS and POM in the R tanks $(r=0.99)$ as well as in the NR tanks $(r=0.90)$. However, average \% POM was significantly higher in 

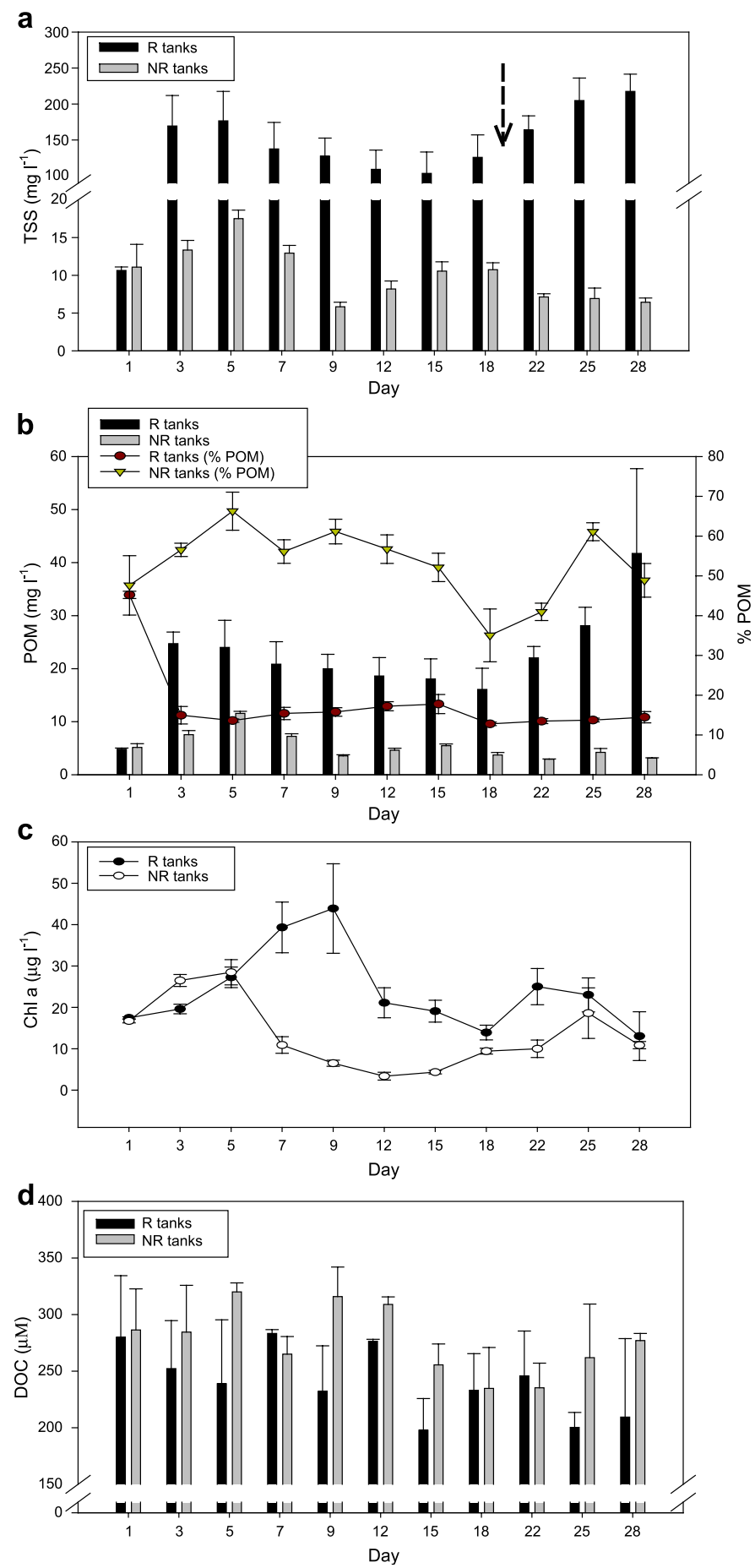

Fig. 1. Average concentrations of the following variables in the R and NR tanks (Experiment 1). (a) TSS concentration. (b) POM and \% POM. (c) Chl $a$ concentration. (d) DOC concentration. Error bars show standard deviations of three replicates in each system. 
the NR tanks $(53 \pm 1 \%)$ than the R tanks $(18 \pm 0.9 \%)$ (Fig. 1b). While POM in the R tanks decreased during the off-cycle, there was a significant increase in \% POM $(26 \pm 2 \%, n=3)$ in the $\mathrm{R}$ tanks, compared to the on-cycle. This was because the large amount of sediment particles, which were transferred to the water column during resuspension events, settled rapidly during the off-cycle. In addition, the higher \% POM in the NR tanks was partially due to the roughly double biomass of zooplankton throughout the experiment compared to the $\mathrm{R}$ tanks. Polychaete larvae, however, was about threefold higher in biomass in the $\mathrm{R}$ tanks than the NR tanks.

In both systems, two distinct phytoplankton "blooms" occurred during the experiment with an earlier bloom in the NR tanks compared to the R tanks (Fig. 1c). Chl $a$ in the R tanks was significantly higher on average than the NR tanks, averaging $24 \pm 2$ and $13 \pm 0.9 \mu \mathrm{g} 1^{-1}$, respectively. These results appear counter-intuitive to expectation (i.e. increased turbidity would result in a reduction of primary productivity). In corroboration, Wainright (1987) also found that planktonic microbial growth was stimulated by resuspended sediments. In addition, other studies have demonstrated that sediment microbial production (e.g. benthic bacteria and microalgae) and settled phytoplankton are transferred to the water column during resuspension (Wainright, 1990). However, it appears that this is not the case for our experiment as Chl $a$ during the on-cycle was not significantly different from that of the off-cycle, suggesting that benthic phytoplankton were not transferred to the water column to any significant degree as resuspension occurred. Sloth et al. (1996) similarly found in their mesocosm experiment that less than $2 \%$ of the benthic algal chlorophyll was transferred to the water column during the resuspension period $(2 \mathrm{~h})$. While there were correlations between Chl $a$ and TSS $(r=0.56)$ as well as POM $(r=0.62)$ in the NR tanks, there was no correlation found in the $\mathrm{R}$ tanks. This also supports the contention that benthic phytoplankton was not transported to the water column in any substantial way as resuspension occurred.

DOC in the NR tanks was significantly higher than in the $\mathrm{R}$ tanks, averaging $277 \pm 3 \mu \mathrm{M}(\mathrm{NR})$ and $241 \pm 8 \mu \mathrm{M}(\mathrm{R})$ during the on-cycle (Fig. 1d). There are no data available during the off-cycle. The range in DOC falls well within the range found in the Chesapeake Bay $(160-500 \mu \mathrm{M})$ where TSS varies from 5 to $30 \mathrm{mg} \mathrm{l}^{-1}$ (Mason et al., 1999). As mentioned earlier, the higher biomass of zooplankton may explain the higher DOC in the NR tanks because DOC can be produced by zooplankton excretion. In fact, Park et al. (1997) found a significant correlation between labile DOC production rates and zooplankton densities in their outdoor continuous flow-through pond experiment.

Table 1 presents the water chemical characteristics measured daily (during the on-cycle) over the experiment period. The salinity and temperature were similar in both systems. DO and $\mathrm{pH}$ in the NR tanks were higher than those in the R tanks.

\subsubsection{Mercury distribution}

The average concentration of particulate $\mathrm{THg}$ (on a mass basis) was significantly higher in the $\mathrm{R}$ tanks than the NR tanks, being $2.3 \pm 0.1(\mathrm{R})$ and $1.1 \pm 0.05$ nmol g ${ }^{-1}$ (NR) (Fig. 2a). This suggests that resuspended sediments contributed to higher particulate $\mathrm{THg}$ in the R tanks. Unfortunately, there are no data available for the first 9 days due to loss of the samples. Even during the off-cycle (non-resuspension), a similar pattern was observed (e.g. significantly higher particulate THg in the R tanks). The average concentration of particulate $\mathrm{THg}$ was not significantly different in the $\mathrm{R}$ tanks during the off-cycle, compared to the on-cycle.

Although sediment data are not discussed here, sediment cores were taken from all the $\mathrm{R}$ and NR tanks for $\mathrm{Hg}$ analyses (Kim et al., 2004). The average concentrations of $\mathrm{THg}$ in the top sediment

Table 1

Average and standard deviation for ancillary parameters in the water column of the R and NR tanks during the course of experiments 1 and 2

\begin{tabular}{llrr}
\hline & Parameters & \multicolumn{1}{c}{$\mathrm{R}$ tanks } & NR tanks \\
\hline Experiment 1 & DO $\left(\mathrm{mg} \mathrm{l}^{-1}\right)$ & $5.7 \pm 1.2$ & $8.5 \pm 1.5$ \\
& Salinity (ppt) & $14 \pm 0.3$ & $14 \pm 0.3$ \\
& Temperature $\left({ }^{\circ} \mathrm{C}\right)$ & $25 \pm 1.2$ & $25 \pm 1.3$ \\
& $\mathrm{pH}$ & $7.7 \pm 0.2$ & $8.1 \pm 0.3$ \\
Experiment 2 & $\mathrm{DO}\left(\mathrm{mg} \mathrm{l}^{-1}\right)$ & $6.7 \pm 0.8$ & $8.2 \pm 1.3$ \\
& Salinity (ppt) & $19 \pm 0.2$ & $19 \pm 0.2$ \\
& Temperature $\left({ }^{\circ} \mathrm{C}\right)$ & $20 \pm 1.9$ & $20 \pm 2.0$ \\
& $\mathrm{pH}$ & $7.5 \pm 0.3$ & $7.8 \pm 0.2$ \\
\hline
\end{tabular}



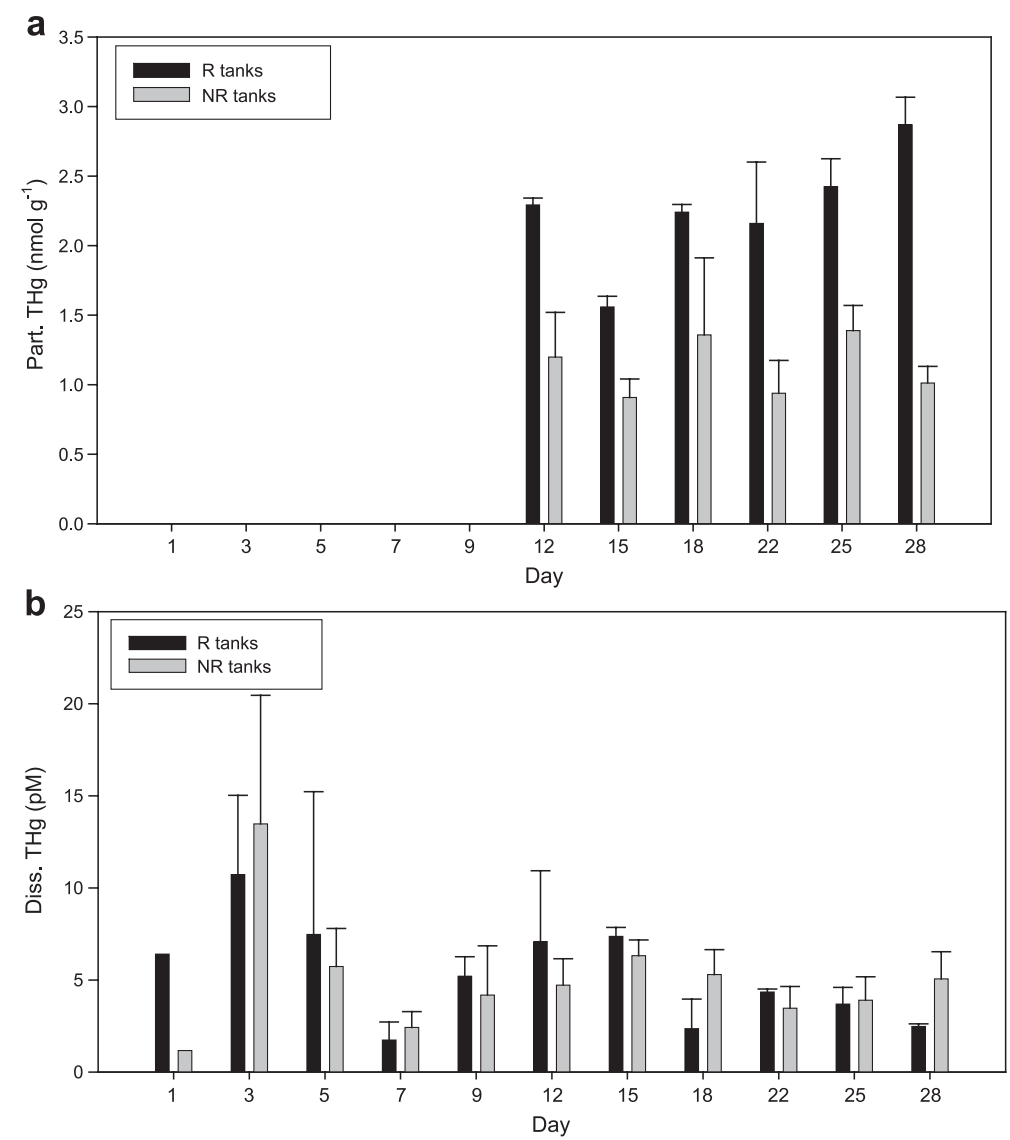

Fig. 2. Average concentrations of THg in particulate and dissolved phases in the R and NR tanks (Experiment 1). (a) Particulate THg concentration. (b) Dissolved THg concentration. Error bars show standard deviations of three replicates in each system.

$(0-0.5 \mathrm{~cm})$ were $2.6 \pm 0.3(\mathrm{R})$ and $2.3 \pm 0.8 \mathrm{nmol}$ $\mathrm{g}^{-1}$ (dry weight) (NR) at the end of the experiment. In the $\mathrm{R}$ tanks, $\mathrm{THg}$ in surface sediment was comparable with particulate $\mathrm{THg}$ in the water column but this was not the case in the NR tanks. Given that the unfiltered ambient water added at the beginning of the experiment was from the Patuxent River and that this was the major source of particles for the NR tanks, besides in site production, it was possible that $\mathrm{THg}$ in the water column would be similar to that in the Patuxent River. Our THg data (particulate + dissolved THg on a pM basis) in the water column fell within the range of $\mathrm{THg}$ in unfiltered Patuxent River water reported by Benoit et al. (1998). In addition, phytoplankton growth would change the average concentration of $\mathrm{THg}$ on particles. Overall, particulate THg in the water col- umn in the $\mathrm{R}$ tanks also represented its origin (i.e. from the sediment during resuspension).

Dissolved $\mathrm{THg}$, unlike particulate $\mathrm{THg}$, was remarkably similar between the two systems, averaging $5.5 \pm 1.0 \mathrm{pM}$ and varied during the experiment period (Fig. 2b). As mentioned earlier, there was a water exchange every day at a rate of $10 \%$ with ambient filtered water. Input water was also collected for $\mathrm{Hg}$ analysis three times throughout the experiment period (days 18, 22, and 28). The average concentration of input water was $3.0 \pm 0.5 \mathrm{pM}(n=3)$. The disparity of dissolved THg concentrations between the input water and the mesocosms could be due to daily fluctuations of THg concentration in the input water or could reflect $\mathrm{Hg}$ input from the suspended particle phase or from the sediment. There was no significant difference in dissolved $\mathrm{THg}$ between the resuspension 
and non-resuspension phases in the R tanks, suggesting that particle desorption processes were not occurring substantially during resuspension. Overall, the dissolved THg did not seem to change in concert with changes in the particulate $\mathrm{THg}$. This suggests that particles and water did not reach equilibrium very quickly (i.e. not on the timescale of the on- and offcycles), or that $\mathrm{Hg}$ bound to particles was not available for exchange.

Mason et al. (1999) estimated that $70-80 \%$ of the dissolved THg was bound to DOC in the Chesapeake Bay. There was, however, no correlation found between DOC and the dissolved THg in this experiment. DOC in our experiment ranged from 131 to $321(\mathrm{R})$ and 208 to $333 \mu \mathrm{M}(\mathrm{NR})$. It is possible that the lack of correlation results from the small range of DOC found in the mesocosoms. Similarly, Lacerda and Gonsalves
(2001) did not find a significant correlation between DOC and dissolved $\mathrm{THg}$ in waters of the coastal lagoons of Rio de Janeiro, Brazil probably due to the small range of DOC $(516-733 \mu \mathrm{M})$ and the limited data set. In contrast, Conaway et al. (2003) found that dissolved $\mathrm{THg}$ was significantly correlated with DOC in the San Francisco Bay estuary, USA, where DOC ranged widely (e.g. from 80 to $890 \mu \mathrm{M}$ ).

Particulate and \% MeHg are presented in Fig. 3a, showing an opposite trend to particulate $\mathrm{THg}$. The concentration of particulate $\mathrm{MeHg}$ was significantly higher in the NR tanks than in the R tanks, averaging $34 \pm 5.0$ and $11 \pm 2.0 \mathrm{pmol} \mathrm{g}^{-1}$, respectively. Although $\% \mathrm{MeHg}$ was available only from the 12th day onwards due to the sample loss for particulate $\mathrm{THg}$, it was also higher in the NR tanks than the R tanks. This difference likely resulted from the introduction of
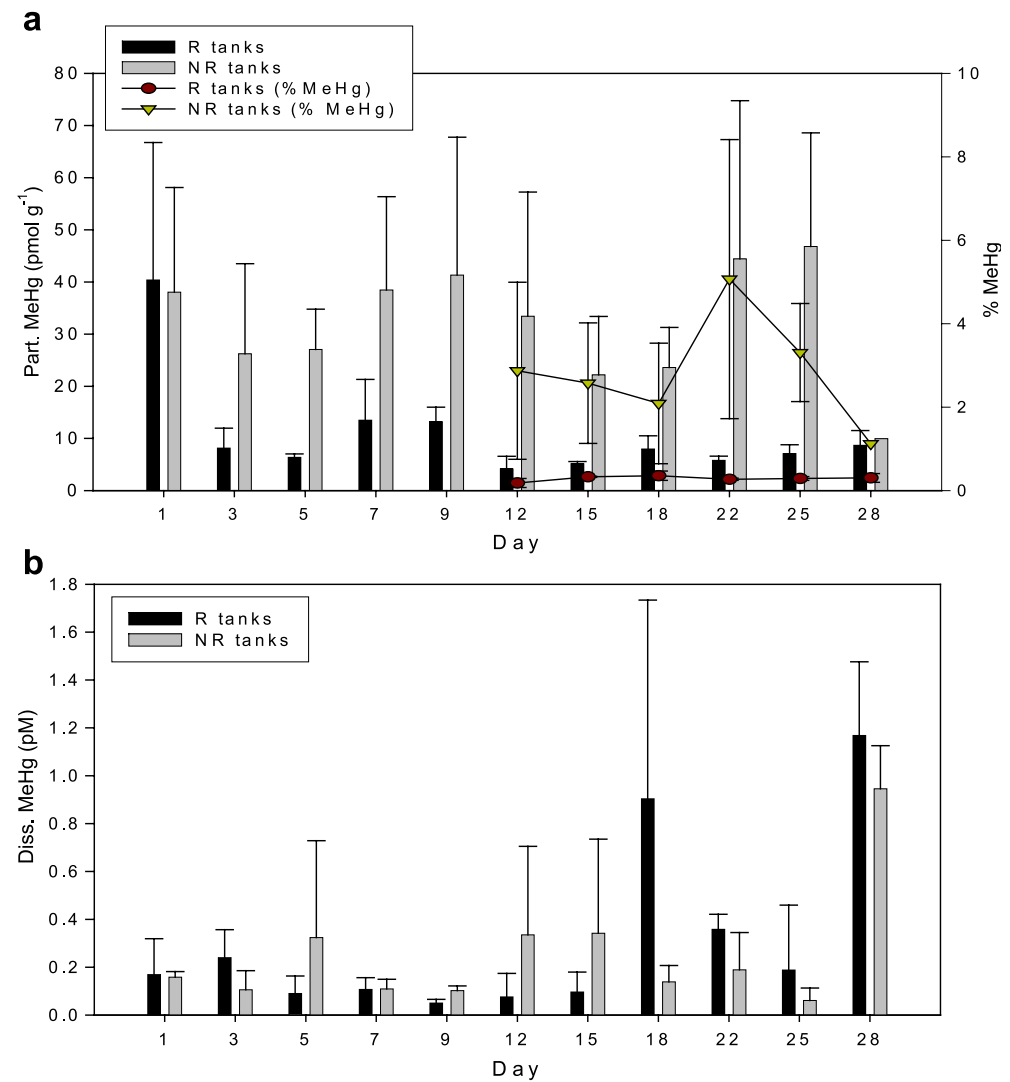

Fig. 3. Average concentrations of MeHg in particulate and dissolved phases in the R and NR tanks (Experiment 1). (a) Particulate MeHg concentration. (b) Dissolved MeHg concentration. Error bars show standard deviations of three replicates in each system. 
sediment particles that contained lower $\mathrm{MeHg}$ concentration $(<1 \%$ of $\mathrm{THg})$ to the water column during resuspension. While sediment particles were dominant in the R tanks, TSS was mostly plankton in the NR tanks. During the off-cycle, particulate $\mathrm{MeHg}$ in the $\mathrm{R}$ tanks increased significantly $\left(26 \pm 6.5 \mathrm{pmol} \mathrm{g}^{-1}\right.$, $n=3$ ), compared to the on-cycle, as sediment particles, primarily less $\mathrm{MeHg}$-rich particles, settled quickly. Particulate $\mathrm{MeHg}$ per gram increased due to its higher concentrations in the higher POM nonsettling particles, a large fraction of which was likely plankton. As mentioned earlier, \% POM actually increased in the $\mathrm{R}$ tanks during the off-phase. In addition, particulate $\mathrm{MeHg}$ (on a pM basis) was significantly correlated with $\mathrm{Chl} a(r=0.35)$ and POM $(r=0.78)$ in the $\mathrm{R}$ tanks and similarly with Chl $a(r=0.39)$ as well as POM $(r=0.34)$ in the NR tanks. As mentioned earlier, NR tanks had higher \% POM and zooplankton biomass. Sediment $\mathrm{MeHg}$ $\left(5.0 \pm 1.0 \mathrm{pmol} \mathrm{g}^{-1}\right)$ in the $\mathrm{R}$ tank was comparable to particulate $\mathrm{MeHg}$ in the water column during the on-phase while sediment $\mathrm{MeHg}\left(5.0 \pm 2.5 \mathrm{pmol} \mathrm{g}^{-1}\right)$ was lower than particulate MeHg in the NR tanks. As mentioned earlier, these sediment $\mathrm{MeHg}$ data were from the averages respectively of all the $\mathrm{R}$ and NR tanks in the end of experiment.

Dissolved MeHg in both systems varied throughout the experiment, as observed for dissolved THg. The average concentrations of dissolved $\mathrm{MeHg}$ were $0.3 \pm$ $0.2(\mathrm{R})$ and $0.3 \pm 0.1 \mathrm{pM}$ (NR) (Fig. 3b). Again, dissolved $\mathrm{MeHg}$ did not appear to change in concert with particulate $\mathrm{MeHg}$ in both systems. As mentioned before, dissolved concentration seemed to be influenced by the incoming water as much as by partitioning between particles and dissolved fractions. The average $\mathrm{MeHg}$ concentration in the inflow water was $0.5 \pm 0.5$ $\mathrm{pM}(n=3)$. No significant correlation was found between the dissolved $\mathrm{MeHg}$ and DOC in both systems, as observed for dissolved THg and DOC.

\subsubsection{Distribution coefficients}

The relative affinity of $\mathrm{Hg}$ for dissolved and particulate phases is often parameterized by the distribution coefficient: $K_{\mathrm{d}}=S / D\left(\mathrm{~kg}^{-1}\right)$; where $S=$ concentration of $\mathrm{Hg}$ sorbed to particles (ng $\left.\mathrm{kg}^{-1}\right)$, calculated as [particulate $\mathrm{Hg}\left(\mathrm{ng} \mathrm{l}^{-1}\right)$ ]/TSS $\left(\mathrm{kg} \mathrm{l}^{-1}\right)$; and $D=$ dissolved concentration (ng $1^{-1}$ ). A higher $K_{\mathrm{d}}$ value indicates a higher affinity for the particulate phase.
Table 2 shows the average water column distribution coefficient $\left(\log K_{\mathrm{d}}\right)$ and standard deviation for $\mathrm{THg}$ and $\mathrm{MeHg}$ in this experiment. The $K_{\mathrm{d}}$ values for both $\mathrm{THg}$ and $\mathrm{MeHg}$ were in a similar range to those found for other aquatic systems (Babiarz et al., 1998; Coquery et al., 1997; Mason and Sullivan, 1997; Muhaya et al., 1997; Stordal et al., 1996). In experiment 1 , lower $K_{\mathrm{d}}$ values were found for $\mathrm{MeHg}$ than for THg. Others have found this pattern, for example, Benoit et al. (1998) found in the Patuxent River that the $\log K_{\mathrm{d}}$ for $\mathrm{MeHg}(3.8-4.0)$ was lower compared to that for $\mathrm{THg}(4.8-5.7)$.

The $K_{\mathrm{d}}$ for $\mathrm{THg}$ in the $\mathrm{R}$ tanks was significantly higher than in the NR tanks during both cycles because of higher particulate $\mathrm{THg}$ (on $\mathrm{nmol} \mathrm{g}^{-1}$ basis) in the $\mathrm{R}$ tanks. There was, however, no significant difference in $K_{\mathrm{d}}$ for THg in the R tanks between the two cycles. This was because particulate $\mathrm{THg}$ in the $\mathrm{R}$ tank remained relatively constant between the two cycles. The $K_{\mathrm{d}}$ for MeHg in the NR tanks was significantly higher only during the on-cycle compared to the R tanks. Coquery et al. (1997) observed a lower $K_{\mathrm{d}}$ value with increasing TSS, which has been noted by others (Honeyman and Santschi, 1989) and which is explained by the increase of the proportion of colloidal material in the filter passing (so-called dissolved) fraction with increasing TSS. Lawson et al. (2001) showed that the $K_{\mathrm{d}}$ values for both THg and $\mathrm{MeHg}$ decreased with particulate organic content, confirming the notion that $\mathrm{Hg}$ binding to suspended

Table 2

Average and standard deviation for $\log K_{\mathrm{d}}$ in the R and NR tanks during the course of experiments 1 and 2

\begin{tabular}{llll}
\hline & $\log K_{\mathrm{d}}$ & $\mathrm{R}$ tanks & NR tanks \\
\hline Experiment 1 & $\mathrm{THg}$ (on) ${ }^{\mathrm{a}}$ & $5.7 \pm 0.05$ & $5.4 \pm 0.06$ \\
& $\mathrm{THg}$ (off) & $5.8 \pm 0.07$ & $5.5 \pm 0.1$ \\
& $\mathrm{MeHg}$ (on) & $4.8 \pm 0.2$ & $5.3 \pm 0.1$ \\
Experiment 2 & $\mathrm{MeHg}$ (off) & $5.1 \pm 0.6$ & $5.2 \pm 0.06$ \\
& $\mathrm{THg}$ (on) & $5.6 \pm 0.09$ & $5.4 \pm 0.05$ \\
& $\mathrm{THg}$ (off) & $5.4 \pm 0.09$ & $5.2 \pm 0.1$ \\
& $\mathrm{MeHg}$ (on) & $4.7 \pm 0.2$ & $5.2 \pm 0.3$ \\
& $\mathrm{MeHg}$ (off) & $4.9 \pm 1.1$ & $5.2 \pm 0.5$ \\
\hline
\end{tabular}

\footnotetext{
${ }^{\mathrm{a}}$ On-cycles when both resuspension and water mixing system were on in the R tanks while in the NR tanks only water mixing was on.

${ }^{\mathrm{b}}$ Off-cycles when both resuspension and water mixing were ceased in the R tanks. Off-cycles in the NR tanks means there was no water mixing. See the text for details.
} 
particulate involves complexation to organic material. Others have found similar results (Bloom et al., 1999; Mason and Sullivan, 1998). Here, while the presence of colloidal material may explain the results, it is more likely that the effect is due to the higher relative $\mathrm{MeHg}$ concentration of the smaller particulate, living and dead, which does not settle during the off-cycle compared to the quickly settling larger particles. This notion is given credence by the fact that the $K_{\mathrm{d}}$ for $\mathrm{MeHg}$ in the $\mathrm{R}$ tanks during the off-cycle is very similar to that of the NR tanks.

\subsection{Experiment 2 (with clams)}

\subsubsection{Water column characteristics}

The concentration of TSS was significantly higher in the R tanks than the NR tanks, averaging $63 \pm 22$ (R) and $4.5 \pm 0.6$ (NR) $\mathrm{mg}^{-1}$ (Fig. 4a). As mentioned in experiment 1 , there were three time samplings of the resuspension off-cycle (days 4,10 , and 17). In the $R$ tanks, average TSS significantly decreased during the off-cycle $\left(9.5 \pm 2.2 \mathrm{mg} \mathrm{l}^{-1}, n=3\right)$ compared to the on-cycle, which was a similar pattern with that in experiment 1 . However, TSS concentrations were about half those of experiment 1 . Less TSS in the NR tanks was due to a combination of clam feeding on phytoplankton and lower temperature compared to that in experiment 1 . Less TSS in the $\mathrm{R}$ tanks likely resulted from a change in sediment properties as the sediment from experiment 1 was reused for experiment 2 . In addition, TSS tended to decrease toward the end of experiment, suggesting that clams in the $\mathrm{R}$ tanks were active in removing particulate from the water column, or that initially clams destabilize sediments and increased resuspension in the initial part of the experiment.

POM was significantly higher in the $\mathrm{R}$ tanks than the NR tanks, averaging $10 \pm 4.2(\mathrm{R})$ and $2.0 \pm 0.2$ $\mathrm{mg}^{-1}$ (NR) (Fig. 4b). The average POM in the $\mathrm{R}$ tanks decreased significantly to $2.5 \pm 0.4 \mathrm{mg}^{-1}$ $(n=3)$ during the off-cycle compared to the on-phase. POM was positively correlated with TSS in both R tanks $(r=0.77)$ and NR tanks $(r=0.96)$, as observed in experiment 1. Overall, POM in experiment 2 showed a similar pattern with that in experiment 1 . The average POM in experiment 2, however, was also less than that in experiment 1 due to a decrease in TSS in the water column. In addition, although it is not possible to directly compare zooplankton biomass between the two experiments due to differences in water temperature, salinity, and clam presence, this biomass decreased roughly by $80 \%$ in the R tanks and $87 \%$ in the NR tanks in experiment 2 , compared to experiment 1 . One explanation for a zooplankton decrease could be due to reduced food availability. As discussed later, less standing stock of phytoplankton was observed in experiment 2, compared to experiment 1 , potentially as a result of not only lower water temperature (Table 1) but also clam feeding. Percent POM was significantly higher in the NR tanks, averaging $46 \pm 2.3 \%(\mathrm{NR})$ and $16 \pm 0.7 \%(\mathrm{R})$ (Fig. 4b). In the $\mathrm{R}$ tanks, \% POM significantly increased to $29 \pm 6.6 \%(n=3)$ during the off-cycle compared to the on-cycle, as seen in experiment 1. Overall, \% POM was similar in both sets of the tanks during the two experiments.

There was a small phytoplankton bloom observed in the $\mathrm{R}$ tanks later in this experiment while there was an overall decreasing trend in Chl $a$ in the NR tanks (Fig. 4c). As seen in experiment 1, Chl $a$ was significantly higher in the $\mathrm{R}$ tanks than NR tanks, averaging $6.7 \pm 0.3$ and $3.6 \pm 0.1 \mu \mathrm{g} 1^{-1}$, respectively. Compared to experiment $1, \mathrm{Chl} a$ concentration in both systems decreased by $72 \%$ as water temperature was lower in experiment 2. Chl $a$ in the R tanks was significantly higher during the on-cycle compared to the off-phase $\left(5.3 \pm 0.9 \mu \mathrm{g}^{-1}, n=3\right)$. In experiment 1 , however, there was no significant difference in $\mathrm{Chl}$ $a$ between the two cycles in the $\mathrm{R}$ tanks. This was probably due to larger variability in Chl $a$ in experiment 1 . In addition, Chl $a$ was not correlated with either TSS or POM in the R tanks, whereas there was a positive correlation between Chl $a$ and TSS ( $r=$ $0.48)$ and POM $(r=0.46)$ in the NR tanks, as observed in experiment 1 . The lower Chl $a$ standing stock in this experiment results from a combination of lower water temperature as well as the existence of clams in both systems. As in experiment 1, DOC data were available only during the on-cycle (Fig. 4d). Although the average DOC in the NR tanks $(325 \pm 10$ $\mu \mathrm{M})$ was higher than that in the $\mathrm{R}$ tanks $(297 \pm 54$ $\mu \mathrm{M})$, the difference was not significant.

Water column characteristics for experiment 2 are presented in Table 1. These measurements were made during the on-cycle. More diurnal fluctuation in temperature was observed in experiment 2 . A heating 

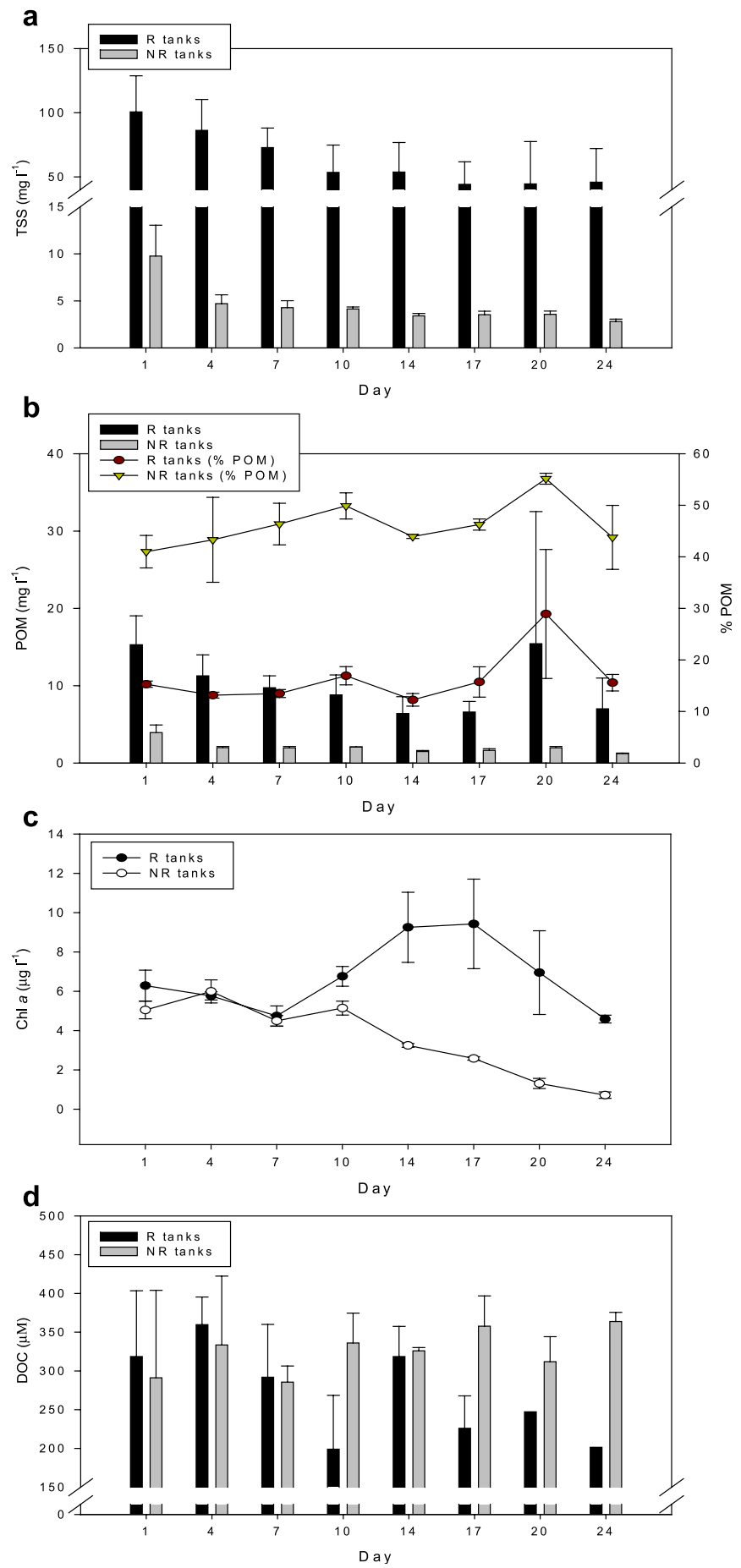

Fig. 4. Average concentrations of the following variables in the R and NR tanks (Experiment 2). (a) TSS concentration. (b) POM and \% POM. (c) Chl $a$ concentration. (d) DOC concentration. Error bars show standard deviations of three replicates in each system. 
system was occasionally used when the water temperature was unusually low in order to prevent large temperature differences potentially harmful to the ecological community in the mesocosms. As seen in experiment $1, \mathrm{DO}$ and $\mathrm{pH}$ were slightly higher in the NR tanks than the R tanks. Sloth et al. (1996) found that oxygen concentration decreased by $5 \%$ during a 2-h resuspension event in their mesocosm experiment and that the decrease in oxygen content corresponded to an oxygen consumption rate of $500 \mathrm{mmol} \mathrm{m}^{-2}$ day $^{-1}$, or 10 times the normal oxygen consumption rate of the sediment. They suggested that the increase in oxygen consumption was probably due to liberation of pools of reduced inorganic and organic products from anaerobic processes in the sediment. Similar procedures are likely consuming DO in the $\mathrm{R}$ tanks in our experiment.

\subsubsection{Mercury distribution}

Particulate $\mathrm{THg}$ was significantly higher in the R tanks than the NR tanks, as seen in experiment 1 , averaging $2.3 \pm 0.2(\mathrm{R})$ and $1.4 \pm 0.05 \mathrm{nmol} \mathrm{g}^{-1}$ (NR) (Fig. 5a). Particulate THg (on a nmol $1^{-1}$ basis) was significantly correlated with TSS $(r=0.97)$ and POM $(r=0.77)$ in the R tanks, as seen in experiment 1 . In addition, there was a significant correlation between particulate THg and TSS $(r=0.39)$, as well as POM $(r=0.40)$, in the NR tanks. The lack of correlation between particulate THg and TSS or POM found in experiment 1 was unexpected because

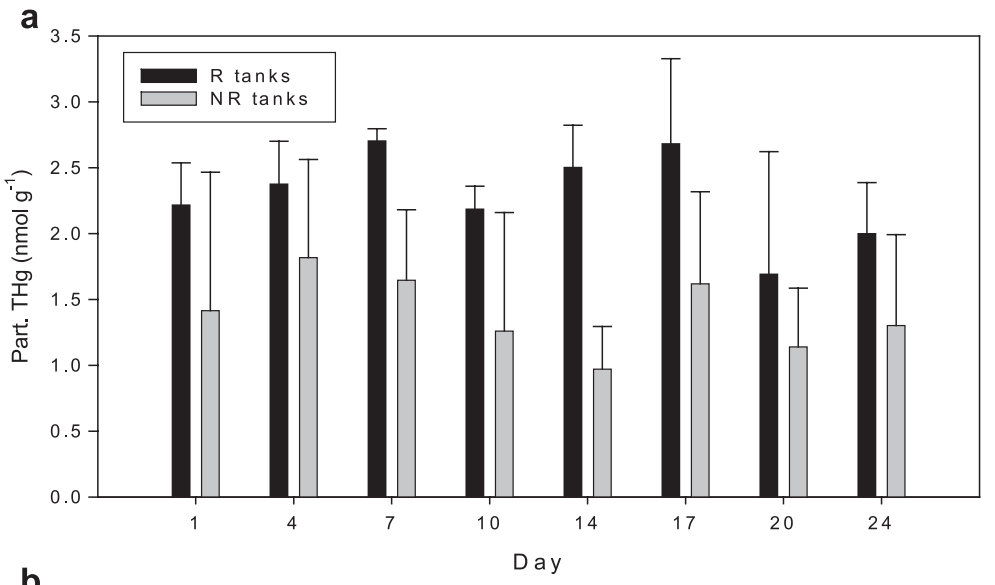

b

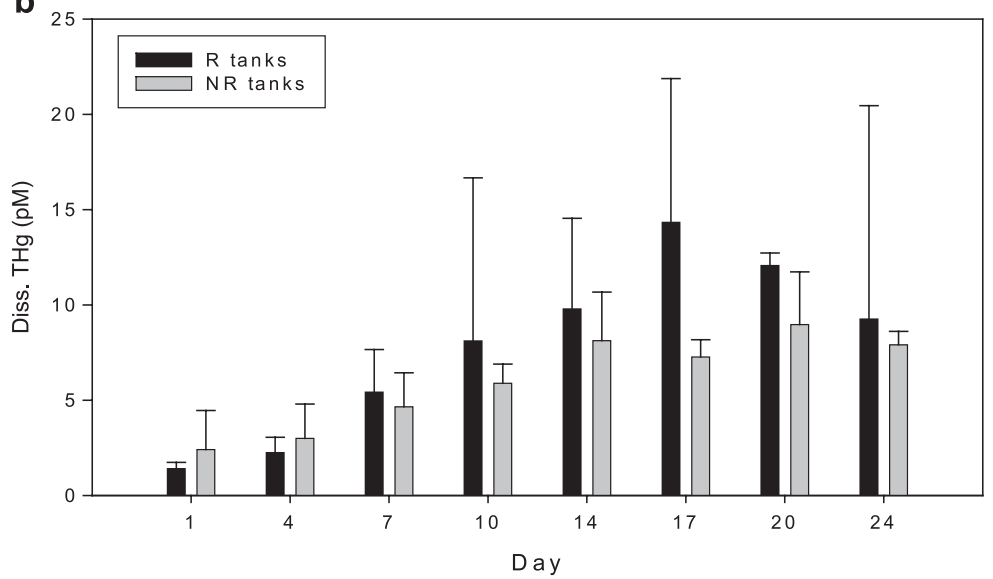

Fig. 5. Average concentrations of THg in particulate and dissolved phases in the R and NR tanks (Experiment 2). (a) Particulate THg concentration. (b) Dissolved THg concentration. Error bars show standard deviations of three replicates in each system. 
$\mathrm{Hg}$ is one of the most strongly particle-associated metals. This was probably because of the smaller data set in experiment 1 due to sample loss. In experiment 2 , sediment cores were also taken from all the tanks in the end of the experiment for $\mathrm{Hg}$ analysis (Kim et al., 2004). The average concentrations of surface sediment $\mathrm{THg}$ in the cores were $1.8 \pm 0.5$ (R) and $1.3 \pm 0.4 \mathrm{nmol} \mathrm{g}^{-1}(\mathrm{NR})$, showing a slightly lower range than that in experiment 1 . This was likely due to inherent sediment heterogeneity, as discussed in Kim et al. (2004).

Dissolved THg was significantly higher in the R tanks than the NR tanks, as seen in Fig. 5b. The average concentrations of dissolved $\mathrm{THg}$ were $8.0 \pm 0.5(\mathrm{R})$ and $6.0 \pm 0.3 \mathrm{pM}(\mathrm{NR})$. A similar range of dissolved THg was found during the off-phase. Dissolved THg tended to increase toward the end of the experiment. However, the change in dissolved $\mathrm{THg}$ did not correspond to the change in particulate $\mathrm{THg}$, as seen in experiment 1 . Dissolved THg in the input water was measured also for the same sampling days, except the 4th day. A similar range of THg in the input water was found (average of $7.0 \pm 5.5 \mathrm{pM}$ ). Given that water exchange was always done after sampling, dissolved $\mathrm{THg}$ in the mesocosms did not directly represent the concentration of $\mathrm{THg}$ in the input water on the corresponding day. Nonetheless, it appears that dissolved THg in the tanks may have been driven as much by the change in the incoming water than by the release of $\mathrm{THg}$ from particles upon resuspension.

Particulate $\mathrm{MeHg}$ was significantly higher in the NR tanks than the R tanks, averaging $26 \pm 5.0$ (NR) and $6.0 \pm 1.0 \mathrm{pmol} \mathrm{g}^{-1}(\mathrm{R})$, as seen in experiment 1 (Fig. 6a). The percent MeHg was also higher in the
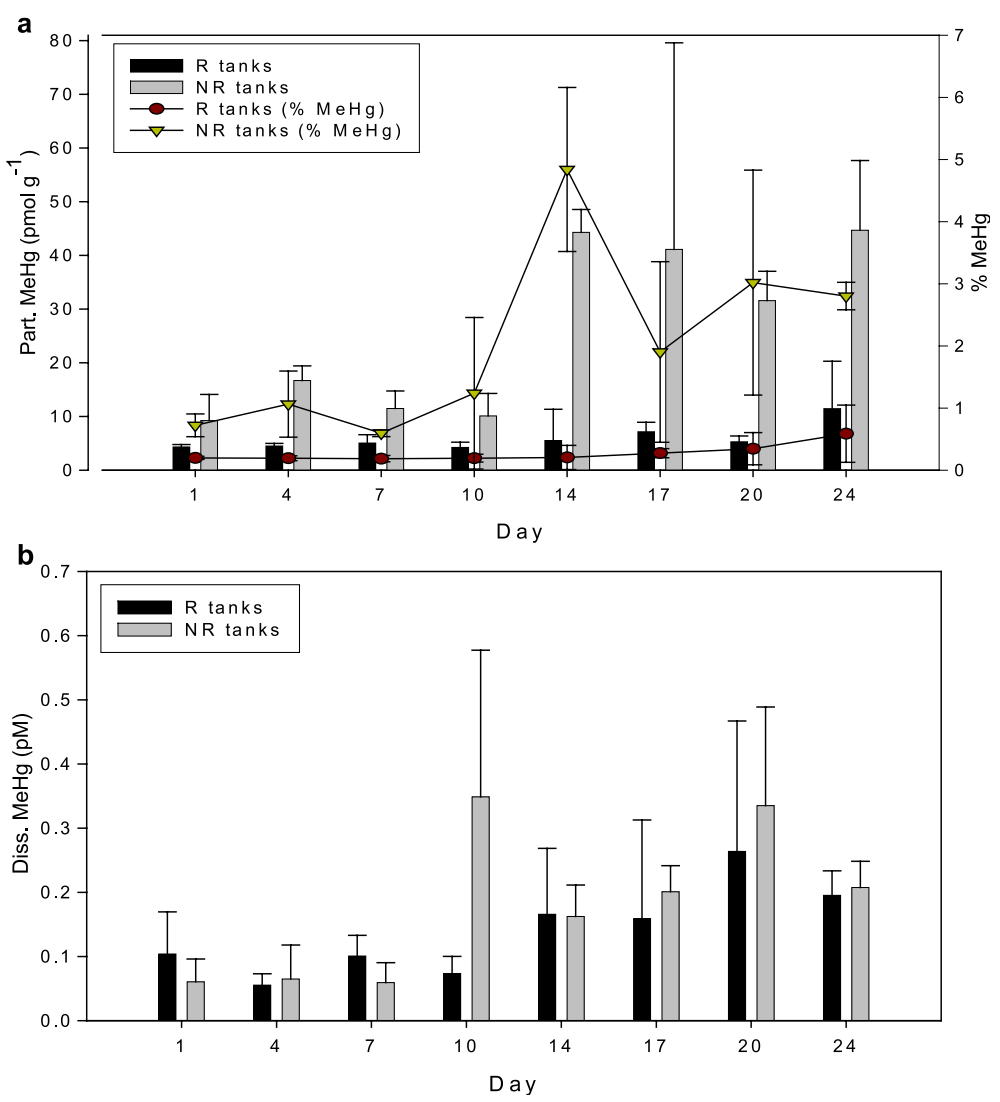

Fig. 6. Average concentrations of $\mathrm{MeHg}$ in particulate and dissolved phases in the R and NR tanks (Experiment 2). (a) Particulate MeHg concentration. (b) Dissolved MeHg concentration (on). Error bars show standard deviations of three replicates in each system. 
NR tanks than the R tanks throughout the experiment. During the off-cycle, the average concentration of particulate $\mathrm{MeHg}$ increased to $15 \pm 7.0 \mathrm{pmol} \mathrm{g}^{-1}$ $(n=3)$ in the R tanks. It appears that particulate $\mathrm{MeHg}$ was somewhat diluted by material of lower $\mathrm{MeHg}$ during the on-phase and higher particulate $\mathrm{MeHg}$ was found during the off-phase, as TSS decreased (concentration effect). The average concentrations of $\mathrm{MeHg}$ in surface sediments were similar between the two systems, being $5.0 \pm 0.5(\mathrm{R})$ and $5.0 \pm 0.4$ pmol $\mathrm{g}^{-1}$ (NR) from all the tanks. The result showed that sediment $\mathrm{MeHg}$ was comparable to particulate $\mathrm{MeHg}$ in the $\mathrm{R}$ tanks (during the on-cycle) but lower than that in the NR tanks.

There was a significant correlation between particulate $\mathrm{MeHg}$ (on a pM basis) and TSS $(r=0.76)$ as well as POM $(r=0.57)$ in the R tanks. Particulate $\mathrm{MeHg}$ was also significantly correlated with particulate THg $(r=0.77)$ but not with $\mathrm{Chl} a$ in the R tanks. The lack of correlation between particulate $\mathrm{MeHg}$ and Chl $a$ may be due to the smaller range of Chl $a$ concentration compared to experiment 1 . It is interesting that particulate $\mathrm{MeHg}$ was negatively but significantly correlated with POM $(r=-0.41)$ as well as Chl $a(r=-0.37)$ in the NR tanks while there were positive correlations found in experiment 1 .

The average concentration of dissolved $\mathrm{MeHg}$ was $0.2 \pm 0.05$ (NR) and $0.2 \pm 0.05$ pM (R) (Fig. 6b). As seen in experiment 1 , dissolved $\mathrm{MeHg}$ was remarkably similar in both systems. The average concentration of dissolved $\mathrm{MeHg}$ in the input water was $0.2 \pm 0.1 \mathrm{pM}$, which was in a similar range of $\mathrm{MeHg}$ found in the mesocosms. Overall, it is unlikely that resuspension increased dissolved $\mathrm{MeHg}$ in the water column, suggesting that release due to oxidation of sulfide phases, or other processes enhancing desorption, were not significant.

\subsubsection{Distribution coefficients}

As seen in experiment 1 , the average $K_{\mathrm{d}}$ for $\mathrm{THg}$ was significantly higher in the R tanks than the NR tanks during both cycles (Table 2 ). The average $K_{\mathrm{d}}$ for $\mathrm{MeHg}$ was significantly higher in the NR tanks during the on-cycle only, as seen in experiment 1 . These observations suggest that there are two types of particles in the R tanks: one that is relatively inorganic, consisting mostly of sediment particles, which does not release $\mathrm{Hg}$ rapidly (non-reactive) and the other that is reactive and takes up $\mathrm{Hg}$ actively, or is in which $\mathrm{Hg}$ is readily exchangeable. Also, it appears that the non-reactive particles had a higher $\mathrm{THg}$ than the reactive ones. However, these concentrations in the $\mathrm{R}$ tanks were similar to that of the surface sediment. The much higher $\mathrm{Hg}$ in the non-reactive particles results in the trends observed for the two experiments. The opposite was observed for $\mathrm{MeHg}$ in that the $K_{\mathrm{d}}$ was higher in the NR tanks than the R tanks during the on-phase, suggesting that suspended particles were actively accumulating $\mathrm{MeHg}$ compared to the sediment. In addition, the $K_{\mathrm{d}}$ for $\mathrm{MeHg}$ in the R tanks was higher during the off-phase in both experiments 1 and 2 when TSS concentration was lower as most of resuspended sediment particles settled quickly.

Scaling calculations for $\mathrm{Hg}$ uptake in phytoplankton confirm that uptake by phytoplankton would not lead to enhanced particulate $\mathrm{Hg}$ concentration in the water column, given the relatively high sediment $\mathrm{Hg}$ concentration. Based on the Chl $a$ concentration in the $\mathrm{R}$ tanks during the off-phase, and some reasonable assumptions about phytoplankton size and growth rate, the data in Mason et al. (1996) can be used to estimate the steady state phytoplankton $\mathrm{Hg}$ burden under the experiment conditions. A range in $\mathrm{Hg}$ concentration of $0.3-0.5 \mathrm{nmol} \mathrm{g}^{-1}$ is estimated, much lower than the sediment load i.e. uptake of $\mathrm{Hg}$ from the dissolved phase is unlikely to significantly alter the $\mathrm{Hg}$ burden in the suspended particles and thus no difference is expected between the on-phase (sediment particles dominant) and the off-phase (phytoplankton more dominant).

Similar calculations for $\mathrm{MeHg}$ give a range in values of 5-30 $\mathrm{pmol} \mathrm{g}^{-1}$, comparable to the measured values in the NR tanks and in the R tanks during the off-phase. Thus, active uptake by phytoplankton could be influencing the overall $\mathrm{MeHg}$ particulate load given that the steady state phytoplankton $\mathrm{MeHg}$ is higher than that of the surface sediments. Thus, our scaling arguments confirm the observations and measurements. While this uptake into biota is important in defining the $\mathrm{MeHg}$ concentration on a pmol $\mathrm{g}^{-1} \mathrm{TSS}$ basis, it is not an important sink for dissolved $\mathrm{MeHg}$ given the large size of the tank (1000 1) and the estimated rate of uptake.

Additionally, a similar pattern in dissolved $\mathrm{THg}$ and $\mathrm{MeHg}$ in both $\mathrm{R}$ and $\mathrm{NR}$ tanks show that dissolved and particulate fractionation cannot be 
explained purely by equilibrium partitioning. As suggested above, THg is more particle associated and strongly bound to the non-living (or sediment) fraction that cycles between the water column and the sediment, with very little release during resuspension. Heyes et al. (in review) found from a Hudson River study that particulate THg in the water column was mostly bound to reactive phases, such as iron oxides and amorphous iron sulfide, and organic phases and that $\mathrm{Hg}$ partitioning on resuspended particles did not change over a tidal diurnal cycle resuspension event. In contrast to inorganic $\mathrm{Hg}, \mathrm{MeHg}$ partitioning appears to be controlled more by the biotic fraction that actively accumulates $\mathrm{MeHg}$.

\subsubsection{Mass balance calculations}

A simple mass balance provides useful insights into $\mathrm{MeHg}$ fate and production. Given measured concentrations in input waters, and in the tanks during the off-phase, the following is estimated: experiment 1 input of $\mathrm{MeHg} \sim 50 \mathrm{pmol} \mathrm{day}^{-1}$ with output of $\sim 55$ pmol day $^{-1}$ for the NR tanks and $\sim 80 \mathrm{pmol} \mathrm{day}^{-1}$ for the $\mathrm{R}$ tanks, which have higher TSS. Thus, it appears that $\mathrm{MeHg}$ is produced within the $\mathrm{R}$ mesocosms and that the methylation rate is overall higher in the $\mathrm{R}$ system. Our results for $\mathrm{Hg}$ methylation in the sediment, which are contained in Kim et al. (2004), confirm this notion of higher methylation in the R tanks. However, the overall net rate derived from mass balance is low compared to what others have measured for estuarine sediments using $\mathrm{Hg}$ core spike incubations (Benoit et al., 1998) and compared to our rates from core incubations of these sediments. As suggested by others, these results suggest that while core spike incubation experiments give a relative measure of the methylation rate between treatments, they do not provide an accurate estimate of in situ methylation. These mesocosom studies therefore provide useful information about net $\mathrm{MeHg}$ production in estuarine systems that are not easily obtained by other approaches.

The results of the mesocosm experiments suggest that resuspension can enhance $\mathrm{MeHg}$ production. While this may appear counter-intuitive, the likely explanation is that the oxygenation of the sediment that results from resuspension reduces sediment AVS and pore water sulfides in estuarine sediments and thus improves the methylation environment by enhancing $\mathrm{Hg}$ bioavailability to bacteria, by mechanisms proposed by Benoit et al. (1999). Furthermore, in an estuarine system, or any aquatic system with high $\mathrm{TSS}$, the fate of $\mathrm{Hg}$ will be linked closely to that of the particulate phase. Thus, from a mass balance perspective, understanding the sediment transport is crucial in ascertaining whether the system will be a net source or sink for $\mathrm{Hg}$. For $\mathrm{MeHg}$, this is less true, even given the high $K_{\mathrm{d}}$ for $\mathrm{MeHg}$ in many environments as internal sources of $\mathrm{MeHg}$ (i.e. $\mathrm{Hg}$ methylation) are likely a complicating factor in the overall $\mathrm{MeHg}$ mass balance.

\section{Summary}

Our experiments showed that significant amounts of particulate $\mathrm{THg}$ in the $\mathrm{R}$ tanks were introduced to the water column by resuspension. However, particulate $\mathrm{MeHg}$ was found to be significantly lower than that in the NR tanks. Dissolved concentrations of THg and $\mathrm{MeHg}$ showed a similar pattern between the two systems and appeared little impacted by sediment load. The dynamics between the dissolved and particulate phases in these experiments suggests that the notion of equilibrium partitioning for $\mathrm{Hg}$ is not valid. There appears to be two types of particles, those that readily accumulate and/or potentially release $\mathrm{Hg}$ and $\mathrm{MeHg}$, and those that do not. Our mass balance calculation suggests that resuspension likely enhances $\mathrm{MeHg}$ production in these sediments.

\section{Acknowledgements}

We would like to thank the crew of Aquaris at CBL for their help getting the sediments from Baltimore Harbor. We also thank the Hudson River Foundation (HRF) for their support (grant no. 009-01A), Cherrystone Aqua Farms in Cheriton, VA, USA for providing clams, and the Analytical Service at CBL for analyzing samples. Our research was also supported by grant no. R 824850-01-0 from USEPA STAR program as part of the Multiscale Experimental Ecosystem Research Center (MEERC) at the University of Maryland Center for Environmental Science (UMCES).

Associate editor: Dr. Patrick Buat-Menard. 


\section{References}

Arfi, R., Guiral, D., Bouvy, M., 1993. Wind induced resuspension in a shallow tropical lagoon. Estuar. Coast. Shelf Sci. 36, 587-604.

Babiarz, C.L., Hurley, J.P., Benoit, J.M., Shafer, M.M., Andren, A.W., Webb, D.A., 1998. Seasonal influences on partitioning and transport of total and methylmercury in rivers from contrasting watersheds. Biogeochemistry 41, 237-257.

Benoit, J.M., Gilmour, C.C., Mason, R.P., Riedel, G.S., Riedel, G.F., 1998. Behavior of mercury in the Patuxent river estuary. Biogeochemistry 40, 249-265.

Benoit, J.M., Gilmour, C.C., Mason, R.P., Heyes, A., 1999. Sulfide controls on mercury speciation and bioavailability to methylating bacteria in sediment pore waters. Environ. Sci. Technol. 33, 951-957.

Bloesch, J., 1995. Mechanisms, measurement and importance of sediment resuspension in lakes. Mar. Freshw. Res. 46, 295-304.

Bloom, N.S., 1989. Determination of picogram levels of methylmercury by aqueous phase ethylation, followed by cryogenic gas chromatography with cold vapor atomic fluorescence detection. Can. J. Fish. Aquat. Sci. 46, 1131-1140.

Bloom, N.S., Crecelius, E.A., 1983. Determination of mercury in seawater at subnanogram per liter levels. Mar. Chem. 14, $49-59$.

Bloom, N.S., Fitzgerald, W.F., 1988. Determination of volatile species at the picogram level by low temperature gas chromatography with cold vapor atomic fluorescence detection. Anal. Chim. Acta 208, 151-161.

Bloom, N.S., Gill, G.A., Cappellino, S., Dobbs, C., Mcshea, L., Driscoll, C., Mason, R.P., Rudd, J., 1999. Speciation and cycling of mercury in Lavaca Bay, Texas, sediments. Environ. Sci. Technol. 33, 7-13.

Brassard, P., Kramer, J.R., Collins, P.V., 1997. Dissolved metal concentration and suspended sediment in Hamilton Harbour. J. Great Lakes Res. 23, 86-96.

Calvo, C., Donazzolo, R., Guidi, F., Orio, A.A., 1991. Heavy metal pollution studies by resuspension experiments in Venice Lagoon. Water Res. 25, 1295-1302.

Conaway, C.H., Squire, S., Mason, R.P., Flegal, A.R., 2003. Mercury speciation in the San Francisco Bay estuary. Mar. Chem. $80,199-225$.

Coquery, M., Cossa, D., Sanjuan, J., 1997. Speciation and sorption of mercury in two macro-tidal estuaries. Mar. Chem. 58, $213-227$.

Cossa, D., Coquery, M., Gobeil, C., Martin, J.-M., 1996. Mercury fluxes at the ocean margins. In: Baeyens, W., Ebinghaus, R., Vasiliev, O. (Eds.), Global and Regional Mercury Cycles: Sources, Fluxes, and Mass Balances. NATO ASI Series. Kluwer Academic Publishing, Dordrecht, pp. 229-247.

Environmental Protection Agency, 1995. Method 1631: mercury in water by oxidation, purge and trap, and cold vapor atomic fluorescence spectrometry. EPA 821-R-95-027, Washington, DC

Evans, R.D., 1994. Empirical evidence of the importance of sediment resuspension in lakes. Hydrobiologia 284, 5-12.

Grizzle, R.E., Bricelj, V.M., Shumway, S.E., 2001. Physiological ecology of Mercenaria mercenaria. In: Kraeuter, J.N., Castagna, M. (Eds.), Biology of the Hard Clam. Elsevier, St. Louis, MO, USA, pp. 305-383.

Heyes, A., Miller, C., Mason, R.P. (in review). Mercury and methylmercury in Hudson River sediment: impact of resuspension on partitioning and methylation. Marine Chemistry.

Honeyman, B.D., Santschi, P.H., 1989. A Brownian-pumping model for oceanic trace metal scavenging: evidence from Th isotopes. J. Mar. Res. 47, 951-992.

Horvat, M., Bloom, N.S., Liang, L., 1993. Comparison of distillation of with other current isolation methods for the determination of methylmercury compounds in low level environmental samples. Anal. Chim. Acta 281, 135-152.

Kim, E.-H., Mason, R.P., Porter, E.T, Soulen, H.L., 2004. The effect of resuspension on mercury methylatoin and bioaccumulation in a shallow estuarine system: a mesocosm study. Mar. Chem. 86, $121-137$.

Lacerda, L.D., Gonsalves, G.O., 2001. Mercury distribution and speciation in waters of the coastal lagoons of Rio de Janeiro, SE Brazil. Mar. Chem. 76, 47-58.

Laima, M.J.C., Matthiesen, H., Lund-Hansen, L.C., Christiansen, C., 1998. Resuspension studies in cylindrical microcosms: effects of stirring velocity on the dynamics of redox sensitive elements in a coastal sediments. Biogeochemistry 43, 293-309.

Latimer, J.S., Davis, W.R., Keith, D.J., 1999. Mobilization of PAHs and PCBs from in-place contaminated marine sediments during simulated resuspension events. Estuar. Coast. Shelf Sci. 49, $577-595$.

Lawson, N.M., Mason, R.P., Laporte, J.-M., 2001. The fate and transport of mercury, methyl mercury, and other trace metals in Chesapeake Bay tributaries. Water Res. 35, 501-515.

Lewis, M.A., Weber, D.E., Stanley, R.S., Moore, J.C., 2001. Dredging impact on an urbanized Florida bayou: effects on benthos and algal-periphyton. Environ. Pollut. 115, 161-171.

Mason, R.P., Lawrence, A.L., 1999. Concentration, distribution, and bioavailability of mercury and methylmercury in sediments of Baltimore Harbor and Chesapeake Bay, Maryland, USA. Environ. Toxicol. Chem. 18, 2438-2447.

Mason, R.P., Sullivan, K.A., 1997. Mercury in Lake Michigan. Environ. Sci. Technol. 31, 942-947.

Mason, R.P., Sullivan, K.A., 1998. Mercury and methylmercury transport through an urban watershed. Water Res. 32, 321-330.

Mason, R.P., Reinfelder, J.R., Morel, F.M.M., 1996. Uptake, toxicity, and trophic transfer of mercury in a coastal diatom. Environ. Sci. Technol. 30, 1835-1845.

Mason, R.P., Lawson, N.M., Lawrence, A.L., Leaner, J.J., Lee, J.G., Sheu, G.-R., 1999. Mercury in the Chesapeake Bay. Mar. Chem. $65,77-96$.

Muhaya, B.B.M., Leermakers, M., Baeyens, W., 1997. Total mercury and methylmercury in sediments and in the polychaete Nereis diversicolor ant Groot Buitenschoor (Scheldt Estuary, Belgium). Water Air Soil Pollut. 94, 109-123.

Park, J.-C., Aizaki, M., Fukushima, T., Otsuki, A., 1997. Production of labile and refractory dissolved organic carbon by zooplankton excretion: an experimental study using large outdoor continuous flow-through ponds. Can. J. Fish. Aquat. Sci. 54, $434-443$. 
Petersen, W., Willer, E., Willamowski, C., 1997. Remobilization of trace elements from polluted anoxic sediments after resuspension in oxic water. Water Air Soil Pollut. 99, 515-522.

Porter, E.T., 1999. Physical and biological scaling of benthicpelagic coupling in experimental ecosystem studies. $\mathrm{PhD}$ dissertation, University of Maryland, College Park, MD.

Porter, E.L., Sanford, L., Gust, G., Porter, F., 2004. Combined water column mixing and benthic boundary-layer flow in mesocosms: key for realistic benthic-pelagic coupling studies. Mar. Ecol., Prog. Ser. (in press).

Sanford, L.P., Panageotou, W., Halka, J.P., 1991. Tidal resuspension of sediments in northern Chesapeake Bay. Mar. Geol. 97, 87-103.

Schoellhamer, D.H., 1996. Anthropogenic sediment resuspension mechanisms in a shallow microtidal estuary. Estuar. Coast. Shelf Sci. 43, 533-548.
Simpson, S.L., Apte, S.C., Batley, G.E., 1998. Effect of short-term resuspension events on trace metal speciation in polluted anoxic sediments. Environ. Sci. Technol. 32, 620-625.

Sloth, N.P., Riemann, B., Nielsen, L.P., Blackburn, T.H., 1996. Resilience of pelagic and benthic microbial communities to sediment resuspension in a coastal ecosystem, Knebel, Vig, Denmark. Estuar. Coast. Shelf Sci. 42, 405-415.

Stordal, M.C., Gill, G.A., Wen, L.-S., Santschi, P.H., 1996. Mercury phase speciation in the surface waters of three Texas estuaries: importance of colloidal forms. Limnol. Oceanogr. 41, 52-61.

Wainright, S.C., 1987. Stimulation of heterotrophic microplankton production by resuspended marine sediments. Science 238, $1710-1712$.

Wainright, S.C., 1990. Sediment-to-water fluxes of particulate material and microbes by resuspension and their contribution to the planktonic food web. Mar. Ecol., Prog. Ser. 62, 271-281. 